\title{
Propiedades físicas de alimento para tilapia roja (Oreochromis spp.) elaborado con ensilado químico y secado en microondas
}

\author{
Yhoan S. Gaviria, Jairo A. Camaño, y José E. Zapata* \\ Facultad de Ciencias Farmacéuticas y Alimentarias. Grupo de Nutrición y Tecnología de Alimentos. Universidad de \\ Antioquia, Medellín, Colombia. (correo-e: edgar.zapata@udea.edu.co)
}

${ }^{*}$ Autor a quien debe ser dirigida la correspondencia.

Recibido Jun. 2, 2020; Aceptado Jul. 29, 2020; Versión final Ago. 17, 2020, Publicado Dic. 2020

\begin{abstract}
Resumen
En esta investigación se analizó la cinética de secado de pellets no extruidos para tilapia roja (Oreochromis spp.). Los pellets son elaborados con insumos convencionales en la dieta control, utilizando secado convectivo y secado con microondas. Se elaboraron pellets con dieta control y una dieta con inclusión de ensilado de vísceras a las que se les determinan los parámetros físicos. El criterio de selección fue la flotabilidad. Los resultados mostraron que el mejor método fue el secado con microondas, el cual entrega pellets con propiedades físicas similares a los extruidos con valores de flotabilidad y relación de expansión entre 63-96\% y 1.6-1.8 respectivamente. Sin embargo, los pellets elaborados con dieta ensilado requieren la aplicación de estrategias de impermeabilización para mejorar su estabilidad en el agua. Se concluye que mediante el secado con microondas se pueden obtener alimentos para tilapia roja con propiedades físicas similares a los obtenidos con métodos convencionales.
\end{abstract}

\section{Physical properties of red tilapia (Oreochromis spp.) feed made with chemical silage and by microwave drying}

\begin{abstract}
The present research study assessed the drying kinetics of non-extruded pellet feed for red tilapia (Oreochromis spp.). The pellets were made with conventional inputs in the control diet by using convective drying and microwave drying. Pellets were made with a control diet and with a diet including viscera silage for which the most relevant physical parameters were determined. The selection criterion was floatability. The results showed that the best method was microwave drying, which delivered pellets with physical properties, floatability (63-96\%) and expansion ratio (1.6-1.8), similar to that of extruded pellets. However, pellets made with a silage diet required the application of waterproofing strategies to improve their stability in water. It is concluded that microwave dried red tilapia feed has similar physical properties to feed made by conventional methods.
\end{abstract}




\section{INTRODUCCIÓN}

En la actualidad, la acuicultura es considerada uno de los sectores alimentarios que presenta la mayor tasa de crecimiento en todo el mundo, esto se debe al constante aumento en la demanda de productos pesqueros, asociado al aumento en la población y al conocimiento que se tiene sobre las características nutricionales y beneficios para la salud de dichos productos (Heller y Keoleian, 2015). Según la FAO (2018), la producción piscícola global ha alcanzado 171 millones de ton, de las cuales el $86 \%$ correspondieron al uso para consumo humano directo, a su vez, informan que la tasa de crecimiento promedio entre el periodo de 2000 a 2016 fue de $5.8 \%$ (FAO, 2018). En Colombia la acuicultura presentó un crecimiento del $75 \%$ en su producción en el año 2018 en comparación con el año 2009, con una producción de 134.807 toneladas, mientras que la tilapia roja (Oreochromis spp.) alcanzó un 65,3\% del total producido (Ministerio de Agricultura, 2019). Este crecimiento va acompañado de un incremento en la generación de residuos, los cuales representan entre 60 y $70 \%$ del total de la producción, que además poseen características nutricionales similares a la especie de la cual provienen, por lo que su inadecuado vertimiento puede afectar las redes tróficas naturales (MartínezAlvarez et al., 2015).

Una de las alternativas de bajo costo que se han propuesto para la revaloración de estos residuos, es el ensilaje, en el que se utilizan las enzimas endógenas (propias del sustrato), las cuales se activan por medio del descenso del $\mathrm{pH}$, para lo cual se adicionan bacterias lácticas, ácidos orgánicos o inorgánicos, con lo que se reduce además la carga microbiana putrefactiva y se favorece la autolisis de la masa, liberando proteínas, péptidos y aminoácidos individuales (Olsen y Toppe, 2017). Es por esto que el ensilado de pescado ha sido utilizado ampliamente como materia prima para diferentes especies de animales como peces sin presentar un efecto negativo sobre su crecimiento y hoy en día es considerado uno de los subproductos más económicos y sostenibles (Davies et al., 2020).

El alimento comprende entre el 50 y $70 \%$ del costo de producción del pescado, impactando directamente la economía del piscicultor, el cual está en constante búsqueda de una producción económicamente viable, por lo que hoy en día se propende por un suministro eficiente, nutritivo y económico para su producción (Mbahinzireki et al., 2015). Por otro lado, los alimentos destinados para peces en especial para tilapia roja (Oreochromis spp.) deben contar con las características físicas adecuadas, las cuales son cruciales para la alimentación, entre estas se destacan estabilidad en el agua, durabilidad, dureza y control en la flotabilidad principalmente, con el fin de evitar la abrasión y fragmentación del pellet, que son necesarios para garantizar un buen sistema de alimentación (Yashni et al., 2020).

La pelletización y la extrusión son los dos métodos principales para producir alimento para peces (De Cruz et al., 2015), estas técnicas en general incluyen etapas básicas como molienda, mezclado, preacondicionamiento, pelletizado y secado (Gao et al., 2019). Estas tecnologías requieren de altos suministros de calor, humedad y presión con el fin de obtener alimentos con la flotabilidad apropiada, disminuir factores anti nutricionales y generar alta digestibilidad, sin embargo, también pueden provocar la pérdida de sustancias termosensibles como vitaminas y ácidos grasos poliinsaturados (Singh et al., 2018). La principal barrera para el uso de la extrusión en las pequeñas explotaciones campesinas, lo representa el costo de los equipos, los cuales no se compensan cuando los volúmenes de producción disponibles son pequeños.

Por otro lado, el secado de los alimentos para peces se lleva a cabo en hornos convectivos entre 40 y $70^{\circ} \mathrm{C}$ dependiendo de las características deseadas (Cian et al., 2018; Glencross et al., 2011; Kamarudin et al., 2018). Este tipo de secado suele presentar tiempos prolongados y formación de costras superficiales debido a las temperaturas elevadas; sin embargo, esto se puede mitigar con el uso de otros métodos de secado como son las microondas (Kumar y Karim, 2019), la cual ha ganado mucho interés en los últimos años debido a que elimina problemas de endurecimiento del producto, aumenta velocidades de transferencia masa, lo que provoca una disminución significativa en el tiempo de secado impactando en la eficiencia energética del proceso (Mujumdar, 2004). Esta técnica tiene múltiples aplicaciones (Kumar y Karim, 2019), sin embargo, el uso en concentrados para animales aun es escasa, pero se ha demostrado que puede ser usada como metodología de secado, puesto que garantiza el cumplimiento de los requerimientos del mercado para estos alimentos (Kumar \& Karim, 2019). El objetivo del presente trabajo fue establecer si un alimento elaborado con ensilaje químico de vísceras de tilapia roja (Oreochromis spp.) y secado por medio de microondas, cuenta con las propiedades físicas requeridas para la alimentación de esta especie.

\section{METODOLOGÍA}

La metodología presenta varias subsecciones, inicialmente se describe la preparación del ensilado químico (EQ), seguido por la formulación y elaboración de dietas alimentarias incluyendo el proceso de pelletización, métodos analíticos, luego se establecen las metodologías de secado convectivo y microondas, toma de datos, parámetros físicos de calidad de los pellets y por último se establece el análisis estadístico. 


\section{Obtención de ensilaje químico}

Las vísceras de tilapia roja (Oreochromis spp.) fueron suministradas por la granja piscícola el Gaitero, ubicada en el municipio de San Jerónimo, Antioquia-Colombia $\left(6^{\circ} 26^{\prime} 30^{\prime \prime} \mathrm{N} 75^{\circ} 43^{\prime} 40^{\prime \prime} \mathrm{W}\right)$ con condiciones climáticas de $30^{\circ} \mathrm{C}$ de temperatura y $65 \%$ de humedad relativa. Estas se recolectaron en recipientes plásticos con geles refrigerantes para garantizar una temperatura de transporte adecuada. Las vísceras fueron desengrasadas calentándolas a $67^{\circ} \mathrm{C}$ durante 30 minutos, dejando descender la temperatura hasta $45^{\circ} \mathrm{C}$, decantando la grasa, para luego llevar a congelación $\left(-18^{\circ} \mathrm{C}\right)$ por $24 \mathrm{~h}$. Con esto se logra una mejor separación del aceite, dado que al solidificarse las fases lo hacen por separado (Arias et al., 2017). Pasado este tiempo se procedió a desprender la fase lipídica de la fase acuosa congelada (rica en proteínas), por medio de un corte transversal y se almacenó hasta el momento de la elaboración del ensilado. Luego, la fase acuosa, se trituró mediante un molino de cuchillas (Black y Decker, USA) para homogeneizarla, se mezcló con $0.03 \%$ de ácido sulfúrico al $97 \%$ (Merck, Alemania) y $1.16 \%$ de ácido fórmico al $85 \%$ (Merck, Alemania) para dar inicio al proceso de hidrólisis y acidificación, sumado a estos se adicionó BHT (Butil hidroxi tolueno) (Tecnas S.A, Colombia) y sorbato de potasio (Tecnas S.A, Colombia) como antioxidante y conservante respectivamente. Finalmente, la mezcla se almacenó a temperatura ambiente durante un tiempo mínimo de 8 días, período en el cual se realizó una homogeneización del producto mediante agitación y control de pH cada dos días, hasta que esté se estabilizó en valor de $\leq 4$.

\section{Formulación de dietas}

Se trabajó con dos dietas, una control (DC) y una con ensilado (DE), estas se formularon de acuerdo con los requerimientos nutricionales para la tilapia roja (Oreochromis spp.) según lo establecido en la directriz del Instituto Colombiano de Agricultura (ICA). La dieta DC utilizó los insumos convencionales, comercialmente disponibles, mientras que la dieta DE, sustituye parte de la Harina de pescado y de la torta de soya, por ensilado de vísceras como fuente de proteína. La formulación y la composición fisicoquímica de las dietas isoproteicas se muestra en la Tabla 1. Las harinas usadas fueron acondicionadas en un molino de cuchillas (NutriBullet, China) obteniendo tamaños de partícula menores a $180 \mu \mathrm{m}$ correspondiente a la serie ASTM $N^{\circ} 80$ (Haver \& M, USA). Se utilizó una premezcla de vitaminas y minerales la cual presenta la siguiente composición por $250 \mathrm{~g}$ de producto: vit. A - 1,400,000 IU; vit. B1 - $500 \mathrm{mg}$; vit. B12 - $300 \mathrm{mg}$; vit. B2 = $500 \mathrm{mg}$; vit. B6 - 1,6 g; vit. D3 - 2,500,000 IU; vit. E - 6,000 IU; vit. K3 = 1,000 mg; biotina - $30 \mathrm{mg}$; niacina - 12 g; acido fólico - $1 \mathrm{~g}$; cobalto - $50 \mathrm{mg}$; cobre - 3,000 mg; hierro - $25 \mathrm{~g}$; yodo - $500 \mathrm{mg}$; manganeso - $32.5 \mathrm{~g}$; selenio $100.50 \mathrm{mg}$; zinc - $22.49 \mathrm{~g}$.

Tabla 1: Composición y Análisis Bromatológico de las Dietas

\begin{tabular}{|l|c|c|}
\hline Materia prima & Dieta control $(\mathrm{g} / \mathrm{kg})$ & Dieta ensilado $(\mathrm{g} / \mathrm{kg})$ \\
\hline Harina de pescado & 240 & 120 \\
\hline Torta de soya & 200 & 80 \\
\hline Harina de maíz & 296.2 & 360 \\
\hline Harina de arroz & 210 & 136.2 \\
\hline Ensilado & 0 & 250 \\
\hline Carbonato de calcio & 6 & 6 \\
\hline Difosfato de calcio & 8 & 8 \\
\hline Premezcla & 5 & 5 \\
\hline Lisina & 15.3 & 15.3 \\
\hline Metionina & 8.1 & 8.1 \\
\hline Treonina & 11.4 & 11.4 \\
\hline Contenido nutricional & \multicolumn{3}{|c|}{} \\
\hline Proteína \% & 31.90 & 33.30 \\
\hline Carbohidratos \% & 33.49 & 36.21 \\
\hline Grasa \% & 6.90 & 8.31 \\
\hline Energía Kcal/kg & 3989 & 4159 \\
\hline Calcio \% & 1.30 & 0.74 \\
\hline Fósforo \% & 1.40 & 0.51 \\
\hline
\end{tabular}

\section{Métodos analíticos}

La caracterización fisicoquímica del EQ y los pellets se realizó de acuerdo con lo establecido por la AOAC (Association of Official Analytical Chemists). El contenido de humedad se determinó mediante la metodología establecida en la norma 930.15 (AOAC, 2000), usando una estufa de convección (Thermo Scientific ${ }^{\text {TM }}$, USA) secando la muestra a $105^{\circ} \mathrm{C}$ durante 8 horas. La proteína se determinó por el método Kjeldahl, norma 954.01 (AOAC, 2000) Kjeldahl (Velp scientifica, Italia). Las cenizas fueron analizadas de acuerdo a la norma 942.05 (AOAC, 2000) (Terrigeno, Colombia). El análisis de grasas según la norma 920.39 (AOAC, 2000) (Radleys, USA). La determinación de carbohidratos se realizó sustrayendo al cien por ciento de la muestra los demás 
componentes mencionados (Spanopoulos-Hernandez et al., 2010). Los análisis microbiológicos se determinaron según lo establecido en la Norma Técnica Colombiana NTC 3688, en la que se establece para este tipo de sustrato el análisis de mesófilos aerobios, coliformes totales y fecales, y mohos y levaduras. El análisis de mesófilos aerobios, mohos y levaduras, fueron realizados empleando el agar plate count (OXOID LTD, Inglaterra) y agar OGYE base según ISO (Merck KGaA, Alemania) respectivamente. El análisis de coliformes totales y fecales fue determinado utilizando el agar EMB (Merck, Alemania).

\section{Elaboración de dietas}

Las materias primas fueron homogeneizadas en un mezclador horizontal de masas con tres hélices ( $E$ \& $M$, Colombia); posteriormente a la dieta control se añadió agua para lograr el contenido de humedad ideal, mientras que para la dieta ensilado se formuló con base en el agua del ensilado químico. Para el proceso de pelletización las mezclas húmedas fueron procesadas en un equipo pelletizador escala laboratorio sin suministro de temperatura ( $E \&$ M, Colombia) el cual consta de un tornillo sin fin simple de $40 \mathrm{~cm}$ de longitud y $5 \mathrm{~cm}$ de diámetro, con una relación de compresión 2:1 y una velocidad de $270 \mathrm{rpm}$. La mezcla fue moldeada mediante un dado de 17 orificios de $5 \mathrm{~mm}$ de diámetro. Los pellets fueron cortados manualmente a un tamaño de $5 \mathrm{~mm}$ de longitud para su posterior secado.

\section{Proceso de secado}

Inicialmente se compararon dos métodos, secado convectivo (SC) y secado con microondas (SM), para determinar cuál de los dos entrega la flotabilidad que el alimento para tilapia requiere. En estos ensayos se utilizó el alimento DC, como alimento modelo, por ser el que cuenta con la composición más convencional. En el secado SC se utilizó una estufa de convección forzada (Thermo Scientific ${ }^{\mathrm{TM}}$, USA) a $60^{\circ} \mathrm{C}$, tomando mediciones de peso cada 30 minutos hasta que la humedad estuviera por debajo de $10 \%$ y se llegara a peso constante. Para el secado con microondas se utilizó un horno AS HM-1.1 (Haceb, Colombia) con potencia máxima de $1.5 \mathrm{kw}$, tomando mediciones de peso cada minuto hasta que la humedad estuviera por debajo de $10 \%$ y se llegara a peso constante. Todas las mediciones fueron tomadas por triplicado de manera discontinua. Se obtuvieron curvas características de secado para cada método, expresadas en porcentaje de humedad (MT) en función del tiempo y velocidad de secado (DV) en función de la humedad (Hammouda y Mihoubi, 2014). MT se calculó con la ecuación 1, donde MH es la masa promedio de los pellets en el momento t y MD corresponde a la masa de la materia seca de la muestra, esta se calculó con base al porcentaje de materia seca determinado gravimétricamente a $105^{\circ} \mathrm{C}$ en estufa de aire Heratherm (Thermo Scientific, España).

La DV se determinó mediante el cálculo directo del cambio en la humedad con respecto al tiempo, como se muestra en la ecuación 2. Con estos datos se calcularon los $D_{\text {ef }}$ para cada método de secado y la flotabilidad de sus respectivas muestras, los cuales se usaron como criterio de selección del mejor método de secado, que luego fue usado para hacer la evaluación de la dieta con ensilado (DE) y contrastarla con la dieta control (DC).

$$
\begin{aligned}
& \mathrm{MT}=\frac{(\mathrm{MH}-\mathrm{MD})}{\mathrm{MH}} * 100 \\
& \mathrm{DV}=\frac{\Delta \mathrm{MT}}{\mathrm{t}}
\end{aligned}
$$

\section{Propiedades físicas y fisicoquímicas de los pellet}

Una vez seleccionado el método de secado con mejor desempeño, se procedió a usarlo con las dos dietas en estudio, a las cuales se les determinó las propiedades más relevantes de los alimentos para tilapia. Para el cálculo del volumen específico (VS) de los pellets, se seleccionaron 10 muestras al azar, se les midió el diámetro y la longitud con un micrómetro digital $0-25 \mathrm{~mm} / 0.001 \mathrm{~mm}$ (Surtek, China), se pesaron y se calculó el VS $\left(\mathrm{cm}^{3} / \mathrm{kg}\right)$ según el método publicado por Cian et al., (2018) con algunas modificaciones. La densidad aparente (DA) fue medida utilizando una probeta de $1000 \mathrm{ml}$, la cual se llenó de pellets para luego registrar su peso, la relación entre peso y volumen de las muestras en el cilindro se expresó en $\mathrm{Kg} / \mathrm{m}^{3}$ (Cian et al., 2018). La relación de expansión (RE) del diámetro del pellet con respecto al diámetro de la boquilla $\left(\mathrm{D}_{b}\right)$ de la pelletizadora se midió seleccionando 10 pellets al azar y haciendo mediciones de diámetro del pellet $\left(\mathrm{D}_{\mathrm{p}}\right)$ con un micrómetro digital $0-25 \mathrm{~mm} / 0.001 \mathrm{~mm}$ (Surtek, China) y utilizando la ecuación 3. La flotabilidad (F) fue determinada según De Cruz et al., (2015), con las modificaciones de Cian et al., (2018), para ello se seleccionaron 10 pellets al azar, se pusieron en un beaker con $100 \mathrm{ml}$ de agua destilada a $25^{\circ} \mathrm{C}$, se determinó el número de pellets flotantes (Nf) suspendidos en el agua después de 30 minutos y se calculó $\mathrm{F}$ con la 
ecuación 4. También se seleccionaron 10 muestras al azar a las cuales se les determinó la dureza según Gao et al., (2019) con un método de punción, utilizando un analizador de textura TA-XT2 (Shimadzu, Japón) equipado con una sonda cilíndrica de $5 \mathrm{~mm}$ de diámetro, una celda de carga de $500 \mathrm{~N}$ y velocidad de $2 \mathrm{~mm} / \mathrm{s}$, se comprimieron los pellets hasta la ruptura. La dureza se expresó como el valor más alto de la fuerza $(\mathrm{N})$ aplicada en la superficie del pellet. Los índices de absorción de agua y solubilidad (WAI y WSI) fueron calculados según De Cruz et al., (2015) con algunas modificaciones, para ello los pellets se molieron y se tamizaron usando un tamiz de $180 \mu \mathrm{m}$, se tomaron $2.5 \mathrm{~g}(\mathrm{Wp})$ de cada muestra y se suspendieron en $30 \mathrm{ml}$ de agua destilada con agitación constante por 30 minutos en un tubo de centrifuga de $50 \mathrm{ml}$, posteriormente se centrifugaron a 3000 gravedades por 10 minutos en una centrifuga U-320R (Boeco, Alemania). El sobrenadante obtenido se vertió en un caja de Petri previamente tarada y se secó a $135^{\circ} \mathrm{C}$ por dos horas en estufa de convección (Thermo Scientific ${ }^{\mathrm{TM}}$, USA), una vez seco el sobrenadante, este fue pesado (Wss) y se calculó WSI con la ecuación 5, mientras que el precipitado en el tubo centrifuga se pesó $\left(\mathrm{W}_{\mathrm{g}}\right)$ para calcular WAI con la ecuación 6 . Todos los análisis fueron realizados por triplicado.

$$
\begin{aligned}
& \mathrm{RE}=\frac{\mathrm{Dp}}{\mathrm{Db}} \\
& \mathrm{F}=\frac{\mathrm{Nf}}{10} \times 100 \\
& \mathrm{WSI}=\frac{\mathrm{Wss}}{\mathrm{Wp}_{\mathrm{p}}} \times 100 \\
& \mathrm{WAI}=\frac{\mathrm{Wg}}{\mathrm{Wp}_{\mathrm{p}}}
\end{aligned}
$$

\section{Determinación de coeficientes de difusividad efectiva $\left(D_{e f}\right)$}

Para el cálculo de los $D_{\text {ef }}$ se utilizó la segunda ley de Fick con la solución analítica desarrollada por Crank (Crank, 1975) teniendo en cuenta las siguientes consideraciones para el transporte de humedad en un material cilindro infinito;1) El sólido es homogéneo e isotrópico; 2) la distribución de humedad es uniforme; 3) la difusión de líquidos es el único transporte de agua en el interior del sólido; 4) la dimensión del solido no varía durante la difusión; 5) el $D_{\text {ef }}$ es constante durante la difusión y 6) el secado se considera bajo condiciones isotérmicas (Da Silva et al., 2010). La ecuación 7 muestra la solución analítica usada por Da Silva et al., (2010), donde MR es la relación de humedad, Meq es la humedad en el equilibrio, Mo es la humedad inicial de la muestra, MT es el contenido de humedad en el tiempo $t, B_{n}$ es un parámetro que viene dado por la ecuación 8 , donde $B_{i}$ es el número de Biot de transferencia de masa, $\mu_{n}$ son las raíces de la ecuación características de un cilindro infinito y $\mathrm{R}$ es el radio del sólido con configuración cilíndrica. Se utilizaron parámetros de números de Biot y raíces encontradas por Da Silva et al., 2010 truncando la serie al quinto término $(n=5)$ donde hay garantías de errores pequeños.

$$
\begin{aligned}
& M R=\frac{M T-M e q}{M o-M e q}=\sum_{n=1}^{\infty} B n \exp \left[\mu n^{2} \frac{D_{\text {ef }}}{R^{2}} t\right] \\
& B_{n}=\frac{4 B^{2}}{\mu n^{2} \frown B^{2}+\mu n^{2}}
\end{aligned}
$$

Se aplicó el método de la pendiente según Karathanos et al., 1990 para el cálculo de la $D_{\text {ef }}$ del agua desde el interior del sólido. Se obtuvo una pendiente de la curva $F_{0}$ vs tiempo, donde $F_{0}$ es el número de Fourier (ecuación 9) encontrados a partir de iteraciones sucesivas de la ecuación 7 en el software "Mathlab" (Licencia 914762, versión 2018) para los datos experimentales. Por último, se utilizó la ecuación 9 para hallar el $D_{\text {ef }}$ utilizando la pendiente de la recta y el radio promedio del alimento (Karathanos et al., 1990).

$$
F_{o}=\frac{\text { Def }}{R^{2}} t
$$




\section{Análisis estadístico}

Los datos recopilados fueron evaluados mediante la prueba de hipótesis para determinar diferencia de medias usando la prueba Dunnett mediante el software statgraphics centurion XVI, con un nivel de confianza del 95\%. Todos los datos se representaron con media \pm desviación estándar (DS).

\section{RESULTADOS Y DISCUSIÓN}

Los resultados presentan los datos de la caracterización de las vísceras frescas y del ensilado obtenido, seguida por los análisis de la cinética de secado y por último se discuten las propiedades físicas de los pellets en función de las dos dietas evaluadas.

\section{Composición bromatológica del ensilado}

En la tabla 2, se observa la composición proximal de las vísceras y el ensilado obtenido de estas. Las vísceras presentan la composición típica de proteína y grasa para esta especie (Arias et al., 2017; Suarez et al., 2018). Por otra parte, los valores encontrados en el ensilado tienden a ser más altos que los reportados para ensilado ácido de residuos de peces de agua dulce con $44.38 \%$ de proteína en base seca y el de ensilado biológico de atún (Thunnus albacares) con $30.52 \%$ de proteína cruda (Spanopoulos-Hernandez et al., 2010). Adicionalmente, el ensilado obtenido evidencia un aumento en el contenido de proteína y un descenso en el nivel de lípidos, con respecto a las vísceras frescas esto debido al proceso de desengrasado.

Tabla 2: Composición Bromatológica de las Vísceras y del ensilado químico Base Seca.

\begin{tabular}{|l|c|c|}
\hline Componente & Vísceras frescas & Ensilado químico \\
\hline Humedad & $61.36 \pm 0.29$ & $82.73 \pm 0.10$ \\
\hline Proteína & $10.45 \pm 0.10$ & $50.89 \pm 0.51$ \\
\hline Carbohidratos & $2.56 \pm 0.09$ & $0.48 \pm 0.04$ \\
\hline Grasa & $85.24 \pm 0.04$ & $39.78 \pm 0.13$ \\
\hline Cenizas & $1.75 \pm 0.04$ & $8.85 \pm 0.02$ \\
\hline
\end{tabular}

EI EQ mostro las características de un ensilado óptimo, con color pardo grisáceo, consistencia semilíquida pastosa y olor característico a pescado (Suarez et al., 2018). El contenido de proteína y grasa lo convierten en insumo ideal para las dietas en alimentación animal, ya que poseen características nutricionales similares a las del pescado de origen (Suarez et al., 2018). Por lo que las proteínas y lípidos del ensilado de desecho de tilapia, cuentan con un perfil nutricional adecuado para especies herbívoras y omnívoras, por tanto este puede ser usado como alternativa a las fuentes convencionales de proteína como son la torta de soya y harina de pescado (Goosen et al., 2014). En el presente trabajo, se logró incluir una fracción considerable de EQ (43.4\% base húmeda), que corresponde a $17.8 \%$ en base seca; esto representa una sustitución de $57.37 \%$ y $23 \%$ de torta de soya y harina de pescado respectivamente, mientras que en otros estudios han utilizado 10 $15 \%$ de ensilado con similares contenidos de proteína y grasa en alimentos para tilapia (Goosen et al., 2014 y Suarez et al., 2018), lo cual es importante de resaltar porque en este caso se estaría maximizando la utilización del ensilado. Por otra parte, la composición microbiológica del EQ se observa en la Tabla 3. Los parámetros se encuentran dentro de los establecido por la directriz técnica Colombiana para materias primas e insumos para alimentación animal del Instituto Colombiano Agropecuario (Ministerio de Agricultura, 2017). Esto indica que el EQ puede ser utilizado como materia prima en la elaboración de alimento para tilapia roja (Oreochromis spp.) sin causar alguna afección o patología en esta especie.

Tabla 3: Composición Microbiológica del EQ

\begin{tabular}{|l|c|c|}
\hline Análisis & Valor & Requisitos \\
\hline Mesófilos aerobios (ufc/ml) & $5 \times 10^{3}$ & $10 \times 10^{5}$ \\
\hline Coliformes totales (ufc/ml) & $3.5 \times 10^{2}$ & $10 \times 10^{4}$ \\
\hline Coliformes fecales & ausencia & ausencia \\
\hline Salmonella spp & ausencia & ausencia \\
\hline Espora Clostridium sulfito & ausencia & $20 \times 10^{1}$ \\
\hline Mohos y levaduras (ufc/ml) & $8.2 \times 10^{2}$ & $10 \times 10^{4}$ \\
\hline
\end{tabular}




\section{Cinéticas de secado}

La curva de pérdida de humedad en el tiempo se puede observar en la figura $1 \mathrm{~A}$, en la que el alimento DC presentó una humedad inicial del $55.0 \%$, para SM se obtuvo una humedad final correspondiente a la humedad de equilibrio de $6.24 \%$ en un periodo de tiempo de 10 minutos, mientras que SC presentó una humedad final del $7.63 \%$ con un tiempo de 330 minutos, como humedad de equilibrio. Esto permite observar como el SM puede reducir exponencialmente hasta 33 veces el tiempo de secado en comparación al SC, esto se debe al calentamiento volumétrico que se produce por la aplicación del microondas, provocando un flujo externo de vapor que escapa rápidamente y como consecuencia genera un aumento en la tasa de velocidad de secado que es reflejada en la presencia de una pendiente más pronunciada en la curva de secado (Mirzabeigi Kesbi et al., 2016; Garg et al., 2019), estos resultados se han encontrado en diferentes matrices como hojaldres (Garg et al., 2019) y rodajas de limón, en las que se ha alcanzado un reducción del tiempo de secado de hasta de 30 veces (Mirzabeigi Kesbi et al., 2016).

(a)

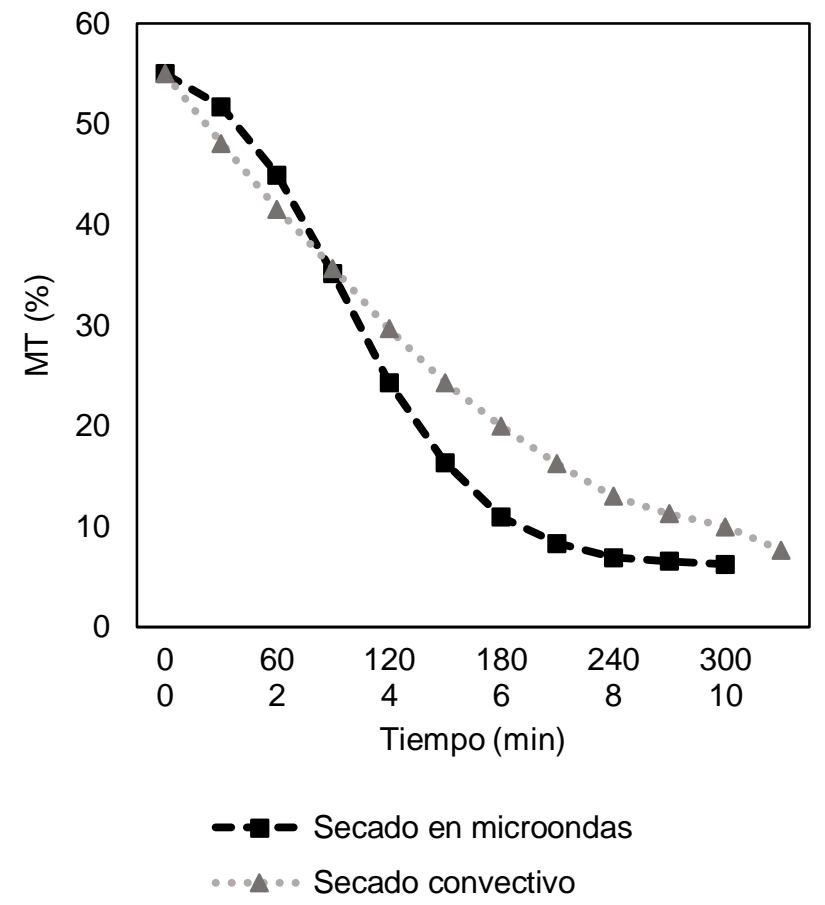

(b)

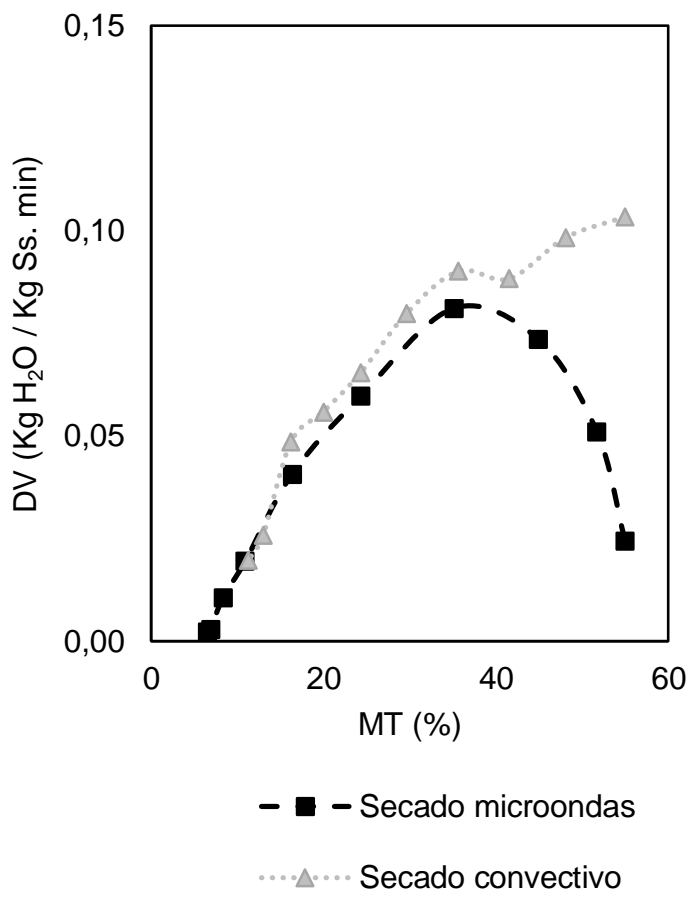

Fig.1: Curvas de secado DC. a) Curva de pérdida de humedad (MT) en función del tiempo. b) Curva de velocidad de secado (DV) en función del contenido de humedad (MT).

La figura 1B correspondiente a la curva de velocidad de secado en función del contenido de humedad, muestra claramente la presencia de las fases típicas de un proceso de secado, en el SC se observa que la velocidad de evaporación del agua al inicio es máxima debido a que la evaporación se lleva a cabo en la superficie de la masa del sólido, mientras que en el SM se observa que esta velocidad va aumentando hasta que alcanza la temperatura de equilibrio húmedo (Hammouda y Mihoubi, 2014); esto es debido a que el sistema carece de un flujo de aire sobre el material, lo que provoca un aumento en la resistencia externa contra la transferencia de humedad en esta fase (Mirzabeigi Kesbi et al., 2016). La fase de secado constante no se logra evidenciar claramente en el SM debido a la ausencia de flujo de aire la cual gobierna esta etapa; luego ocurre una transición, donde se observa la etapa de velocidad decreciente, en la cual, la difusión es el mecanismo que gobierna el secado, donde el agua migra desde el interior de la matriz hasta la superficie a través de los poros (Hammouda y Mihoubi, 2014). Estas curvas muestran un comportamiento similar a lo obtenido por Mirzabeigi Kesbi et al., (2016) con velocidades de secado mayores en SC, sin embargo, Das y Arora, (2018) mostraron que estos parámetros se pueden aumentar utilizando un sistema convectivo asistido con microondas, puesto que mostraron tasas de velocidad de secado mayores en comparación de un SC.

Por otro lado, los $D_{\text {ef }}$ obtenidos para SM y SC fueron $6.54 \times 10^{-10} \mathrm{~m}^{2} / \mathrm{s}$ y $1.63 \times 10^{-11} \mathrm{~m}^{2} / \mathrm{s}$ respectivamente, en los cuales se observa en primer lugar que ambos presentan valores en el rango $10^{-11}$ y $10^{-9}$, que son valores comunes en el secado de alimentos (Olanipekun et al., 2015). Además, se demostró que los $\mathrm{D}_{\text {ef }}$ encontrados en el SM fueron hasta 10 veces mayores con respecto al $D_{\text {ef }}$ para el SC, resultado similar a lo reportado por Das y Arora, (2018) en hongos comestibles, los cuales encontraron valores del orden $10^{-10}$, utilizando microondas como mecanismo de secado. El aumento de estos coeficientes en el SM con respecto SC se 
debe a que en el microondas se genera un mayor aumento de la temperatura, debido a que las ondas penetran el material y producen un calentamiento volumétrico generando vapor de agua dentro de la matriz, lo que permite una mayor velocidad de difusion y gradiente de presion para expulsar al agua del interior del material (Kumar y Karim, 2019). El SC mostró menores valores debido a la naturaleza del proceso, dado que se genera con mayor rapidez un endurecimiento superficial de la matriz provocando una menor difusion efectiva de la humedad (Das y Arora, 2018).

Se ha demostrado que estos mecanismos de secado afectan la estructura matriz, es decir, las caracteristicas físicas y la calidad del producto final están en funcion de la naturaleza del secado. Hoy en día muchas investigaciones se han enfocado en la evaluación del efecto del mecanismo de secado como es el caso de las microondas, sobre los parámetros del producto (Garg et al., 2019). En este caso, para la alimentación de tilapia roja la flotabilidad es el parámetro físico más relevante, este a su vez está en función de la expansión del pellet que se puede generar en el proceso de secado, es así como el secado resulta ser la etapa más crítica del procesamiento de estos alimentos cuando se carece de un proceso de extrusión. En este caso para el SC se obtuvo un $0 \%$ de flotabilidad. Por otro lado para las muestras con SM se obtuvo un $96.67 \%$ de flotabilidad, esto se debe a que en el SC la expansión del pellet se ve limitida por la formación de costras superficiales antes de que la generación y expansión del vapor se pueda dar de forma homogénea en todo el producto (Garg et al., 2019); lo que trae como consecuencia una uniformidad inadecuada de los poros, mientras que el uso de SM evita este tipo de defectos, y genera porosidades uniformes con tamaños pequeños debido al calentamiento volumétrico y distribucion uniforme de la humedad (Garg et al., 2019). De este modo, el SM fue el método de secado seleccionado para llevar a cabo el proceso de elaboracion de las dos dietas alimentarias (DC y DE) para tilapia roja y la evaluación de las propiedades físicas de los pellets obtenidos.

\section{Propiedades físicas del pellet}

La variable humedad se observa en la tabla 4, la cual presentó diferencias estadisticamente significativas entre los tratamientos $(P<0.05)$. Se obtuvieron valores de humedad menores al $12 \%$ para ambas dietas, lo cual indica que son alimentos seguros para el consumo evitando la proliferación de mohos (Ministerio de Agricultura, 2017). Valores similares fueron encontrados por De Cruz et al., (2015) (5\% - 6.5\%) quienes evaluaron diferentes temperaturas de extrusión, para modificar la humedad final del producto. En la tabla 4 se presentan las propiedades físicas de los pellets de ambas dietas sometidas a SM. Se observa que el volumen especifico (VS) es la única propiedad que no presentó diferencias estadisticamente significativas (P $>0.05$ ) entre las dos dietas.

Tabla 4: Propiedades Físicas Secado en Microondas

\begin{tabular}{|c|c|c|c|c|c|c|c|c|}
\hline Dieta & Humedad (\%) & VS $\left(\mathrm{cm}^{3} / \mathrm{g}\right)$ & DA $\left(\mathrm{kg} / \mathrm{m}^{3}\right)$ & RE & $\mathrm{F}(\%)$ & Dureza (N) & WSI (\%) & WAI \\
\hline DC & $6.97 \pm 0.53^{\mathrm{a}}$ & $0.88 \pm 0.12^{\mathrm{a}}$ & $499.70 \pm 2.35^{\mathrm{a}}$ & $1.59 \pm 0.74^{\mathrm{a}}$ & $96.67 \pm 5.77^{\mathrm{a}}$ & $51.97 \pm 1.30^{\mathrm{a}}$ & $18.04 \pm 0.37^{\mathrm{a}}$ & $2.63 \pm 0.43^{\mathrm{a}}$ \\
\hline DE & $5.74 \pm 0.18^{\mathrm{b}}$ & $0.94 \pm 0.15^{\mathrm{a}}$ & $472.70 \pm 7.5^{\mathrm{b}}$ & $1.78 \pm 0.48^{\mathrm{b}}$ & $63.33 \pm 5.77^{\mathrm{b}}$ & $38.67 \pm 2.93^{\mathrm{b}}$ & $21.69 \pm 0.35^{\mathrm{b}}$ & $2.32 \pm 0.37^{\mathrm{b}}$ \\
\hline
\end{tabular}

La densidad aparente (DA) presentó diferencias estadisticamente significativas $(P<0.05)$ entre las dos dietas. Según De Cruz et al., (2015) esta variable es de importancia en el proceso de elaboración de pellets, puesto que está se encuentra directamente relacionada con la flotabilidad del mismo. Se puede observar que los valores de DA se encuentran por debajo del DA máximo establecido para que un pellet flote $\left(530 \mathrm{~kg} / \mathrm{m}^{3}\right) \mathrm{según}$ Glencross et al., (2011). Esto se evidencia en los datos obtenidos para la flotabilidad de ambas dietas, a pesar de que hubo diferencias estadisticamente significativas $(P<0.05)$ entre las dos dietas. Por otro lado los parámetros WSI y WAI, que están fuertemente relacionados con la capacidad del pellet para flotar, también presentaron diferencias estadísticamente significativas entre ambas dietas, siendo conveniente valores mayores de WAI y menores de WSI para obtener mayores porcentajes de flotabilidad. Así mismo estos parámetros son de gran importancia puesto que están asociados con la lixiviación de nutrientes por la desintegración de los pellets (De Cruz et al., 2015; Cian et al., 2018 ). En este caso se observa que el tratamiento DC, el cual presenta un mayor valor en WAI y menor de WSI posee un mayor porcentaje de flotabilidad, siendo estos resultados comparables con los reportados por De Cruz et al., (2015) y Kamarudin et al., (2018). Mientras que el tratamiento DE presenta WSI mayor, con menor flotabilidad, a pesar de contar con menor DA y mayor RE, lo cual puede deberse a la lixiviación de proteinas en el agua, ya que el $E Q$ presenta una alta proporción de proteínas hidrosolubles en su composición (Martínez-Alvarez et al., 2015). Esto indica que este tipo de pellets deben ser impermeabilizados después de elaborados, para reducir su lixiviación y degradación una vez en el agua, y de esa forma mejorar su flotabilidad.

En cuanto a la RE (tabla 4) se tienen diferencias estadísticamente significativas entre las dietas $(P<0.05)$, con valores similares a los reportados por Kamarudin et al., (2018) (1.3) y Gao et al., (2019) (1.65) quienes evaluaron el efecto de la temperatura de extrusión y el efecto del metodo de pelletización y extrusión, sobre 
la calidad de pellets flotantes. Estos resultados demuestran que se pueden lograr pellets con valores de RE similares a los obtenidos en procesos convencionales de extrusión, usando secado con microondas. La variable dureza (tabla 4), presento diferencias estadísticamente significativas $(P<0.05)$ entre las dietas evaluadas, siendo menor para el tratamiento DE. Resultados similares fueron reportados por Sørensen et al., (2009) quienes evaluaron la calidad física de extruidos a base de proteínas de soya. Esta variable posee una relación directa con la $\mathrm{RE}$, puesto que que los pellets que presentan una microestructura más expandida poseen valores de dureza más bajos, ya que el estrés mecánico inducido se centra en los poros de la matriz generando una estructura más frágil (Sørensen et al., 2009).

\section{CONCLUSIONES}

De los resultados mostrados, de su análisis y de su discusión, se puede obtener las siguientes conclusiones, sobre el impacto del proceso de secado de alimento para tilapia roja y su influencia en características del producto: 1) El método de secado tiene efecto sobre la flotabilidad y el $D_{\text {ef }}$ de los pellets para la alimentación de tilapia roja (Oreochromis spp.), siendo el SM el que mejores resultados presenta con respecto al SC; 2) Desde el punto de viste tecnológico el ensilado puede ser usado como materia prima para la elaboración de pellets para tilapia roja (Oreochromis spp.), sin embargo, requiere aplicación de algún tipo de impermeabilizante para mejorar su flotabilidad y estabilidad en el agua; 3) Mediante el secado con microondas, se puede obtener alimentos para tilapia roja (Oreochromis spp.) con propiedades físicas similares a los obtenidos con métodos convencionales que involucran procesos de extrusión con altas temperaturas.

\section{AGRADECIMIENTOS}

Los autores del presente trabajo agradecen a la Universidad de Antioquia y a COLCIENCIAS (proyecto 1115745-58746) por el apoyo financiero brindado para su desarrollo.

\section{NOTACIONES}

\section{Símbolos}

$\mathrm{Bi}=$ Número de Biot de transferencia de masa

$\mathrm{Bn}=$ Parámetro matemático

$\mathrm{DA}=$ Densidad aparente

$D_{\text {ef }}=$ Coeficiente de Difusividad efectiva

$\mathrm{Db}=$ Diámetro de la boquilla

$\mathrm{Dp}=$ Diámetro del pellet

DS=Desviación estándar

$\mathrm{DV}=$ Velocidad de secado

$\mathrm{F}=$ Flotabilidad

Fo= Número de Fourier

$\mathrm{MD}=$ Materia seca de muestra de alimento

$M_{e q}=$ Humedad en equilibrio

$\mathrm{Nf}=$ Número de pellets flotantes

$\mathrm{MH}=$ Masa de alimento en tiempo $\mathrm{t}$

$\mathrm{MR}=$ Relación de humedad

$M_{0}=$ Humedad inicial

$M T=$ Cantidad de humedad en un tiempo $t$

$\mathrm{R}=$ Radio promedio del alimento

$\mathrm{RE}=$ Relación de expansión

$\mathrm{t}=$ Tiempo

$\mu_{\mathrm{n}}=$ Raíces de ecuación

VS= Volumen específico

WAI= Índice de absorción de agua

WSI= Índice de solubilidad

$\mathrm{Wp}=$ Masa inicial de muestra para cálculo de índices

Wss= Masa del sobrenadante seco en el cálculo de índices

$\mathrm{W}_{\mathrm{g}}=$ Masa del precipitado en el cálculo de índices 


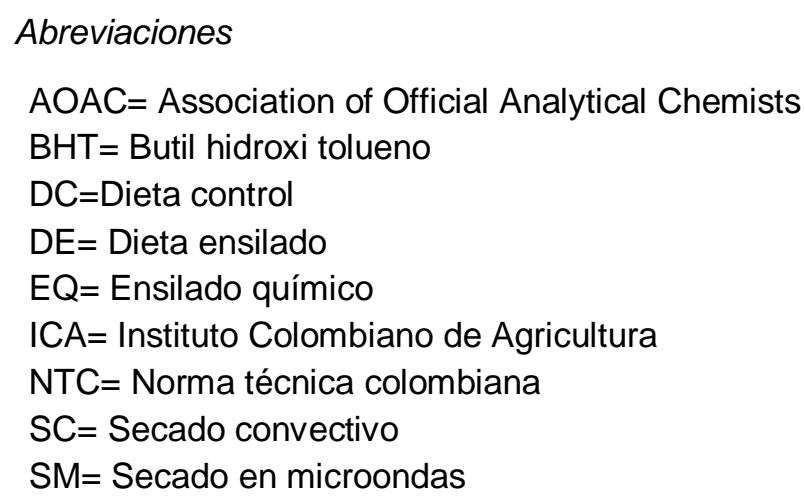

\section{REFERENCIAS}

AOAC, Official Methods of Analysis of AOAC International, 17a Ed; 2-66: Association of Official Analysis Chemists International, Washington, USA (2000).

Arias, L., Gómez, L. J., y Zapata, J. E., Efecto de Temperatura-Tiempo sobre los Lípidos Extraídos de Vísceras de Tilapia Roja (Oreochromis sp.) Utilizando un Proceso de Calentamiento-Congelación, https://do.org/i10.4067/s071807642017000500014 , Inf.Tecnol., 28(5), 131-142 (2017).

Cian, R. E., Bacchetta, C., y otros dos autores., Extruded Fish Feed with High Residual Phytase Activity and Low Mineral Leaching Increased P. mesopotamicus Mineral Retention, https://do.org/10.1016/j.anifeedsci.2018.03.016, Anim. Feed Sci. Tech., 240(March), 78-87 (2018).

Crank, J., The Mathematics of Diffusion, 2da Ed., Clarendon Press, Bristol, UK (1975).

Da Silva, W. P., Precker, J. W., y otros dos autores., Determination of Effective Diffusivity and Convective Mass Transfer Coefficient for Cylindrical Solids via Analytical Solution and Inverse Method: Application to the Drying of Rough Rice, https://do.org/10.1016/j.jfoodeng.2009.12.029n, J. Food Eng., 98(3), 302-308 (2010).

Das, I., y Arora, A., Alternate Microwave and Convective Hot Air Application for Rapid Mushroom Drying, https://do.org/10.1016/j.jfoodeng.2017.10.018 , J. Food Eng., 223, 208-219 (2018).

Davies, S. J., Guroy, D., y otros tres autores., Evaluation of Co-Fermented Apple-Pomace, Molasses and Formic Acid Generated Sardine Based Fish Silages as Fishmeal Substitutes in Diets for Juvenile European Sea Bass (Dicentrachus labrax) Production, https://do.org/10.1016/j.aquaculture.2020.735087 , J. Aquac., 521, (2020).

De Cruz, C. R., Kamarudin, M. S., y otros dos autores., Effects of Extruder Die Temperature on the Physical Properties of Extruded Fish Pellets Containing Taro and Broken Rice Starch, https://do.org/10.1016/j.anifeedsci.2014.11.010, Anim. Feed Sci. Tech., 199, 137-145 (2015).

FAO, The State of World Fisheries and Aquaculture. Meeting the Sustainable Development Goals, Roma, (2018)

Gao, S., Jin, J., y otros cinco autores., Effects of Pelleted and Extruded Feed of Different Ingredients Particle Sizes on Feed Quality and Growth Performance of Gibel Carp (Carassius gibelio var. CAS V), https://do.org/10.1016/j.aquaculture.2019.734236, J. Aquac., 511, (2019).

Garg, A., Malafronte, L., y Windhab, E. J., Baking kinetics of Laminated Dough Using Convective and Microwave Heating. https://do.org/10.1016/j.fbp.2019.02.007, J. Food Bioprod Process., 115, 59-67 (2019).

Glencross, B., Hawkins, W., y otros cinco autores., A Comparison of the Effect of Diet Extrusion or Screw-Press Pelleting on the Digestibility of Grain Protein Products when Fed to Rainbow Trout (Oncorhynchus mykiss), https://do.org/10.1016/j. aquaculture.2010.12.025 , J. Aquac., 312(1-4), 154-161 (2011).

Goosen, N. J., de Wet, L. F., y otros tres autores., Fish Silage Oil from Rainbow Trout Processing Waste as Alternative to Conventional Fish Oil in Formulated Diets for Mozambique Tilapia Oreochromis Mossambicus., https://do.org/10.1016/j.anifeedsci.2013.10.019, Anim. Feed Sci. Tech., 188, 74-84 (2014).

Hammouda, I., y Mihoubi, D., Comparative Numerical Study of kaolin Clay with Three Drying Methods: Convective, Convective-Microwave and Convective Infrared Modes, https://do.org/10.1016/j.enconman.2014.07.085, Energy Convers. Manag., 87, 832-839 (2014).

Heller, M. C., y Keoleian, G. A., Greenhouse Gas Emission Estimates of U.S. Dietary Choices and Food Loss, https://do.org/10.1111/jiec.12174, J. Ind. Ecol., 19(3), 391-401 (2015).

Kamarudin, M. S., de Cruz, C. R., y otros dos autores, Effects of Extruder Die Head Temperature and Pre-gelatinized Taro and Broken Rice Flour Level on Physical Properties of Floating Fish Pellets, https://do.org/10.1016/j.anifeedsci.2017.12.007, Anim. Feed Sci. Tech., 236(December 2017), 122-130 (2018).

Karathanos, V. T., Villalobos, G., y Saravacos, G. D., Comparison of Two Methods of Estimation of the Effective Moisture Diffusivity from Drying Data, https://do.org/10.1111/j.1365-2621.1990.tb06056.x, J. Food Sci., 55(1), 218-223 (1990). 
Kumar, C., y Karim, M. A., Microwave-Convective Drying of Food Materials: A Critical Review, https://do.org/10.1080/10408398.2017.1373269, Crit. Rev. Food Sci., 59(3), 379-394 (2019).

Mbahinzireki, G. B., y otros tres autores, Growth, Feed Utilization and Body Composition of Tilapia (Oreochromis sp.) Fed with Cottonseed Meal-Based Diets in a Recirculating, https://do.org/10.1046/j.1365-2095.2001.00172.x , J. Aquac., 189200 (December 2001).

Martínez-Alvarez, O., Chamorro, S., y Brenes, A., Protein Hydrolysates from Animal Processing by-products as a Source of Bioactive Molecules with Interest in Animal Feeding: A Review, https://do.org/10.1016/j.foodres.2015.04.005, Food Res. Int., 73(1069), 204-212 (2015).

Ministerio de Agricultura, Estrategia de Política para el Sector de Pesca y Acuicultura, Bogota, Colombia, (2019).

Mirzabeigi, O., Sadeghi, M., y Mireei, S. A. Quality Assessment and Modeling of Microwave-Convective Drying of Lemon Slices, https://do.org/10.1016/j.eaef.2015.12.003, Engineering in Agriculture, Environment and Food, 9(3), 216-223 (2016).

Mujumdar, A. S., Research and Development in Drying: Recent Trends and Future Prospects, https://do.org/10.1081/DRT120028201, Dry. Technol., 22(1-2), 1-26 (2004).

Olanipekun, B. F., Tunde-Akintunde, T. Y., y otros tres autores., Mathematical Modeling of Thin-Layer Pineapple Drying, https://do.org/doi.org/10.1111/jfpp.12362, J. Food Process. Pres., 39(6), 1431-1441 (2015).

Olsen, R. L., Toppe, J., Fish Silage Hydrolysates not only a Feed Nutrient, But also a Useful Feed Additive, https://doi.org/10.1016/j.tifs.2017.06.003, Trends Food Sci. Tech., 66, 93-97 (2017).

Singh, P., Shrivastava, V., y Kumar, A., Recent Developments in Greenhouse Solar Drying: A Review. https://do.org/10.1016/j.rser.2017.10.020, Renew. Sustain. Energy Rev., 82(October 2017), 3250-3262 (2018).

Sørensen, M., Stjepanovic, N., y otros tres autores., Soybean Meal Improves the Physical Quality of Extruded Fish Feed, https://do.org/10.1016/j.anifeedsci.2008.05.010, Anim. Feed Sci. Tech, 149(1-2), 149-161 (2009).

Spanopoulos-Hernandez, M., Ponce-Palafox, J. T., y otros cinco autores., Production of Biological Silage from Fish Waste, the Smoked Yellowfin Tuna (Thunnus albacares) and Fillet of Tilapia (Oreochromis sp), for Feeding Aquaculture Species., Rev. Mex. Ing. Quim., 9(2), 167-178 (2010).

Suarez, L. M., Montes, J. R., y Zapata, J. E., Optimización del Contenido de Ácidos en Ensilados de Vísceras de Tilapia Roja (Oreochromis spp.) con Análisis del Ciclo de Vida de los Alimentos Derivados, https://do.org/10.4067/s071807642018000600083, Inf. Tecnol., 29(6), 83-94 (2018).

Yashni, G., AlGheethi, A., y otros cinco autores., Physical Properties of Fish Feed Containing Household Waste as an Alternative Substitute in Newly Developed Soft-Dry Fish Feed for Red Tilapia, https://do.org/10.1016/j.matpr.2020.01.191, Materials Today: Proceedings, 4-7 (2020). 
